\title{
Marxistas, ma non troppo. El derrotero de las ideas de izquierda en el proyecto Nueva Visión
}

\author{
Luciana Del Gizzo ${ }^{1}$
}

Resumen. El proyecto Nueva Visión, conformado por la revista nueva visión (1951-1957) y la editorial homónima fundada en 1955, se planteó desde sus inicios un objetivo modernizador fundado en la síntesis de las artes y la problemática de la forma, que se expresaba en los términos marxistas que muchos de sus miembros, como Tomás Maldonado, Edgar Bayley, Alfredo Hlito, etcétera, habían elaborado en el marco del arte concreto. Sin embargo, el ingreso de ciertas ideas provenientes de la arquitectura y el diseño, como el funcionalismo, el styling o el mismo concepto de diseño industrial "que problematizaba el valor de uso y el valor del producto como mercancía", pondría en tensión la impronta de izquierda. La influencia de Max Bill, a su vez, introducía la necesidad de una apertura crítica y de un antidogmatismo tanto en términos políticos como estéticos, que centraba la atención sobre elementos tan universales como la matemática. A partir del análisis de los artículos aparecidos en la revista nueva visión y de la observación del primer catálogo de la editorial, este trabajo propone reconstruir el derrotero que las ideas de izquierda tuvieron en este proyecto modernizador, con sus tensiones y contradicciones, como un modo de pensar en qué medida los aspectos políticos legitiman un proyecto artístico o condicionan su desarrollo.

Palabras clave: Publicaciones periódicas; nueva visión; marxismo; diseño; arquitectura.

\section{[en] Marxists, ma non troppo. The Path of Leftist Ideas in the Nueva Visión Project}

\begin{abstract}
From its beginning, Nueva Visión project (nueva visión magazine, 1951-1957, and Nueva Visión publishing house founded in 1955) set out a modernizing objective based on the synthesis of the arts and the problem of form. It was expressed in the Marxist terms that many of its members, such as Tomás Maldonado, Edgar Bayley, Alfredo Hlito, etc., had elaborated within the framework of concrete art. However, the new ideas from architecture and design, such as functionalism, styling or the concept of industrial design "that problematized the value of use and the value of the product as a commodity", would question left ideas. The influence of Max Bill, moreover, has introduced the need for a critical opening and antidogmatism in both political and aesthetic terms, which focused attention on mathematics. Analyzing the articles of nueva visión, and studing the first catalog of the publishing house, this paper reconstructs the course of left ideas in this modernizing project, cosidering its contradictions, as a way of thinking to what extent political aspects legitimize an artistic project or condition its development.
\end{abstract}

Keywords: Magazines; new vision; marxism; design; architectur.

Sumario. 1. El origen concreto entre dos constructivismos. 2. De Rusia a Estados Unidos. 3. De la política a la ciencia. 4. Una plataforma de lanzamiento editorial.

Cómo citar: Del Gizzo, L. (2020) Marxistas, ma non troppo. El derrotero de las ideas de izquierda en el proyecto Nueva Visión, en Anales de Literatua Hispanoamericana 49, 39-51.

Las archicitadas palabras del Manifiesto futurista (1909), "nosotros afirmamos que la magnificencia del mundo se ha enriquecido con una nueva belleza, la belleza de la velocidad. [...] un automóvil rugiente, que parece correr sobre la ráfaga, es más bello que la Victoria de Samotracia”, más allá de la alabanza a la aceleración y la técnica, exponían una novedad que se afianzaría a lo largo del siglo XX: la belleza que la

\footnotetext{
${ }^{1}$ Instituto de Literatura Hispanoamericana, Facultad de Filosofía y Letras, Universidad de Buenos Aires-CONICET. Buenos Aires. Argentina. Email: violeta07@gmail.com

Este trabajo es parte del Proyecto de Investigación Plurianual "La legitimación del escritor moderno en América Latina y Europa. Polémicas, operaciones, representaciones" (CONICET/UBA).
} 
producción en serie era capaz de aportar a la vida cotidiana. La cuestión no era original. Los futuristas tomaban posición en un problema que venía planteado desde mediados del siglo XIX por John Ruskin y había sido puesto en práctica en principio por el movimiento Arts \& Crafts de William Morris y luego por el Jugendstil alemán a fines del siglo: el papel que tenía el arte en la fabricación de objetos de uso y la construcción de espacios para habitar, cuando los nuevos materiales y las máquinas eran incapaces de reproducir el costoso estilo artesanal.

La producción en serie requería de nuevas formas estéticas adaptadas al funcionamiento de los objetos y los nuevos materiales, a la vez que abría múltiples e impensadas posibilidades. Declararse a favor de la belleza de un artefacto de forma y funciones nuevas, como el automóvil, implicaba promover un arte opuesto a la ornamentación y a favor de la utilidad, nada más lejos de su autonomía. Aunque es cierto que los futuristas fueron "los primeros en defender la causa de la máquina", la cuestión venía ganando cada vez más adeptos desde fines del siglo anterior con el Movimiento Moderno (Pevsner 2000: 37). El futurismo ruso, que abrevó pronto en las aguas italianas, adoptó esa estética, pero no se planteó el problema de la producción en serie. El constructivismo, en cambio, interpelado por la Revolución Bolchevique, fue en ese sentido al proponer que el artista se integrara a la sociedad como un trabajador más.

A partir de 1921, con la Nueva Política Económica (NEP) del gobierno de Lenin, este movimiento elaboró su plataforma productivista, que procuraba insertar al artista en la cadena de producción. El programa económico mixto de transición hacia el socialismo buscaba equilibrar las cuentas y la producción soviéticas, muy dañadas por la Primera Guerra Mundial y la guerra civil. El plan era establecer un capitalismo de estado, que permitiera la coexistencia de los sectores público y privado: las grandes fábricas estatales tenían el propósito de desarrollar una industrialización similar a la occidental. En ellas, muchos artistas adoptaron fervorosamente el desafío de producir objetos que transformaran la vida cotidiana hacia formas socialistas, sin dejar de considerar el gusto del ama de casa y las limitadas posibilidades de producción, en la transición entre el deseo mercantil capitalista y el anhelo de objetos semisocialistas de la NEP (Kiaer 2010).

Aunque el diseño de objetos, que hace incidir al arte directamente en lo cotidiano a través de la cultura de masas, tenga su origen en esa línea vanguardista y revolucionaria, su desarrollo se vio obturado en la Unión Soviética por la organización del consumo de la economía estalinista a partir de 1929 (Kiaer 2010) y por la política industrial, centrada en la manufactura pesada. Al mismo tiempo, se desplegaba en las economías capitalistas, que buscaban agregar valor a los productos para acrecentar las ventas, yendo a la par de la expansión de cultura de masas, lo que a su vez liquidaba la subversión vanguardista: "La pérdida de fuerza de la vanguardia se vincula con un vasto cambio producido en Occidente durante el siglo veinte: [...] el ascenso de la industria cultural [...] convirtió en obsoleta la empresa misma de la vanguardia" (Huyssen 2006: 24).

Ambos procesos fueron paralelos y mientras el productivismo encontró un modo de generar una relación alternativa entre el arte elevado y la cultura de masas (Huyssen 2006, Kiaer 2010) a través del diseño de objetos socialistas, en el ámbito capitalista el auge de la cadena de producción, como metáfora de la estructura maquínica, requería también pensar un plano estético que redirigiera el deseo de las masas hacia las posibilidades de producción, igual que las industrias soviéticas de la NEP. En otras palabras, la necesidad de transformar la vida cotidiana según los patrones socialistas y la democratización del acceso a productos que supuso la economización de costos del fordismo tenían en común la consolidación de la cultura de masas. El diseño de objetos, desde la óptica de su incipiente teorización, tenía la enorme responsabilidad de guiar el consumo de millones de personas en ambos casos.

Con una muy exigua industrialización, Argentina se encontraba en la periferia de ambos sistemas, entre un capitalismo limitado y el sueño de un socialismo más igualador. La política se percató pronto de la importancia de las masas con el proceso que comenzó el radicalismo a principios de siglo XX y consolidó el peronismo al promediarlo. Sin embargo, la industrialización por sustitución de importaciones se impuso desde los años treinta como consecuencia de la crisis internacional y no por la iniciativa estatal o privada de acrecentar el mercado interno, hasta el gobierno de Juan Domingo Perón, cuando se implementaron algunas medidas para favorecerla. En ese escenario, no parecía pertinente la modernización de los objetos de uso y el diseño quedó relegado hasta casi fines del siglo. 
Sin embargo, la inquietud de la vanguardia, que advierte las expectativas sociales de cambio histórico y materializa en sus experimentaciones el hiato entre lo que ha perdido vigencia y lo que todavía no ha tomado forma ${ }^{2}$, empujó la transformación de los objetos de uso, problematizando la diferenciación entre las bellas artes y las artes aplicadas. En efecto, un grupo de artistas plásticos identificados con la vanguardia concreta y algunos arquitectos de la organización arquitectura moderna $(\mathrm{oam})^{3}$, en fluida relación con el escenario internacional e interesados por el papel del arte en la sociedad, se propusieron modernizar la producción y la recepción de las artes proyectuales mediante un proyecto editorial que incluyó la revista nueva visión (19511957) y la casa editora homónima. Su propósito, más ligado a la actualización de la producción que a la demanda masiva, derivó en una conjugación de sus iniciales ideas marxistas de raíz constructivista con el desarrollo que el diseño de objetos estaba teniendo en las economías de mercado, de cara a un contexto internacional determinado por la segunda posguerra y el Plan Marshall.

Este trabajo busca reconstruir el derrotero de las ideas de izquierda en este proyecto editorial, frecuentemente considerado solo por la historia de las disciplinas artísticas que contempló. El propósito es analizar la circulación de ideologías en ámbitos no propiamente políticos ni puramente intelectuales que, tramadas con otras prácticas culturales, se expusieron a tensiones distintas. Se considerará la labor editorial, como una tarea que, en la selección de los textos y su combinatoria en las páginas de la revista, genera sentidos diversos de los que se desprenden de un libro o de un conjunto de textos de un único autor. Para eso, se procuró observar la publicación en su organización original, sin agrupar sus artículos por tema o por autor, y evitando dar mayor relevancia a los producidos por personalidades que trascendieron posteriormente. Una lectura semejante permite advertir los sentidos que abre el proceso de edición como montaje de textos en una coyuntura particular. A su vez, relevar las ideas de izquierda permitirá considerar en qué medida los aspectos políticos legitimaron la propuesta artística o condicionaron su desarrollo.

\section{El origen concreto entre dos constructivismos}

El proyecto Nueva Visión, conformado por la revista nueva visión (9 números, 1951-1957) y la editorial homónima fundada en 1955, fue propuesto por Tomás Maldonado a su compañero de la Asociación Arte Concreto-Invención, Alfredo Hlito, y a quien se convertiría en pionero del diseño gráfico en Argentina, el Arquitecto Carlos Méndez Mosquera. Desde sus inicios, según informa el número 1, su propósito modernizador se fundó en la síntesis hacia la objetividad y la funcionalidad, para superar la distinción entre artes aplicadas y bellas artes, y vincular a los artistas con la producción en serie. Hasta ese momento, las discusiones del grupo se habían enfocado en cuestiones puramente plásticas como los elementos básicos del lenguaje visual (formas, plano, color) y las leyes de la composición, dado que el arte concreto, heredero del cubismo y el constructivismo de Gabo y Pevsner, buscaba terminar con la representación y manifestarse con formas universales, porque consideraba el arte figurativo como ilusorio y engañoso.

Así entendían la potencia política del arte: por su capacidad de extrañamiento de los sentidos dados, no a partir de formas que remitieran a una realidad fuera de la obra, sino por su fuerza estética real y específica, su capacidad de incidir en el aquí y ahora sin mediación de ninguna lógica externa al objeto artístico. Esta concepción del arte como instrumento político no propagandístico era propio de las ideas de izquierda anteriores al realismo socialista, que exponían en publicaciones como la Revista Arte Concreto-Invención (1946) y el boletín del mismo nombre. La afiliación al Partido Comunista entre 1946 y 1948 no alteró la

${ }^{2}$ Cada vanguardia ha sido un momento de inflexión en el devenir artístico del siglo XX que sustanció lo que ya no era y lo que todavía no tomaba forma, indicando y poniendo de relieve lo que Jauss (2004) denomina umbral de época, es decir, la existencia de un giro en la historia antes de que la sociedad tome plena conciencia del cambio. En ese paréntesis desplegaron su experimentación vacilante, inexacta e incompleta, que conformó lo que llamo una estética de umbral. Para una explicación pormenorizada del concepto de vanguardia como estética de umbral, véase Del Gizzo, Luciana (2017), Volver a la vanguardia. El invencionismo y su deriva en el movimiento poesía buenos aires (1944-1963), MadridBuenos Aires, Aluvión-Ediciones en Danza.

${ }^{3}$ La organización arquitectura moderna (oam) fue una asociación de jóvenes arquitectos conformada por Horacio Baliero, Juan Manuel Borthagaray, Francisco Bullrich, Alberto Casares Ocampo, Alicia Cazzaniga, Gerardo Clusellas, Carmen Córdova, Jorge Goldemberg, Jorge Grisetti y Eduardo Polledo. Se originó en el centro de estudiantes de la Facultad de Arquitectura de la Universidad de Buenos Aires y tuvo continuidad posteriormente en el ejercicio de la profesión y, fundamentalmente, en el desarrollo de la reflexión arquitectónica, mucha de la cual se plasmó en nueva visión. De inspiración vanguardista y modernista, el grupo propuso una renovación de las prácticas proyectuales y arquitectónicas, incluso la integración con otras artes y la reflexión conjunta con el diseño. Estos arquitectos y Tomás Maldonado se influenciaron recíprocamente y compartieron el espacio de trabajo: tanto el estudio de diseño gráfico y comunicación visual axis, de Maldonado y Méndez Mosquera, como la sede de la oam se encontraban en un mítico petit hotel en la calle Cerrito al 1300, demolido una décadas atrás. Para ampliar, véase Deambrosis (2011). 
geometría abstracta de sus obras, que apelaba a la capacidad universal humana de apreciar las formas puras, básicamente, porque la imposición del realismo no había llegado todavía aquí, o bien porque el partido estaba dispuesto a condescender algunas disidencias para ganar adeptos. El estudio de Lucena y Longoni (2003-2004; Lucena 2015) ha mostrado que el PC argentino albergaba a estos artistas entre otras personalidades que tenían posturas estéticas diferentes; de hecho, en la primera posguerra convivían eclécticamente propuestas que iban del realismo a la abstracción ${ }^{4}$.

En 1948, Maldonado viajó a Europa y el periplo lo confirmó como líder del movimiento argentino porque generó una red internacional al vincularse con los concretos suizos -Bill, Graeser, Huber, Loewensberg y el resto del grupo Allianz-, y con los italianos Munari, Dorfles y Dova, entre otros (Lucena 2015, Méndez Mosquera y García 2007), así como con constructivistas -Vantongerloo, Vordemberge-Gildewart, etc. (García 2011)-. Se informó de las ultimísimas tendencias en las que trabajaban, que incluían ideas sobre diseño y tipografía (Méndez Mosquera y García 2007). También se contactó con el PC italiano, cuyos debates, junto con los aspectos políticos elaborados por Allianz, lo convencieron de la necesidad de relajar los dogmas y de generar una apertura crítica (Longoni y Lucena 2003-2004) para pensar problemas más acuciantes para la sociedad que las cuestiones puramente artísticas y que permitiera el desarrollo de disciplinas afines.

El concretismo había surgido en Argentina con una voluntad de síntesis de todas las artes, pero no había logrado más que una interdisciplinariedad reflexiva entre los problemas de la plástica y la poesía. Vuelto de su viaje, Maldonado comenzó a pensar en la dificultad de disciplinas como la poesía y la música para encontrar una aplicación práctica, a diferencia de las artes proyectuales que incidían en la cotidianeidad. Además, el idealismo de la literatura era incómodo para la pretensión de pureza y racionalismo de estas artes: "Es urgente que volvamos a pensar todos nuestros problemas de un modo más estricto, menos literario, menos idealista", expresaba en el número 1 de nueva visión (1951: 5). El idealismo se oponía a la función que tenían los productos de un artista que comenzaba a pensar en la confluencia de las artes aplicadas y las bellas artes, es decir, en el diseño.

Tanto el diseño como la tipografía eran especialidades muy poco desarrolladas en Argentina. Por eso, "las disciplinas proyectuales se transformaron en un nuevo horizonte para la investigación", que requería una publicación propia (Méndez Mosquera y García 2007: 180). Además, la apertura crítica podía abordarse mejor desde áreas afines, como la arquitectura, el urbanismo y el diseño industrial, que compartían preocupaciones y ofrecían soluciones precisas "al problema más dramático y agudo del espíritu de nuestro tiempo, o sea, la situación del divorcio existente entre arte y vida", dado que desarrollaban "interacciones más funcionales" (Maldonado 1949: 7) ${ }^{5}$. Su utilidad permitía introducir el arte en lo cotidiano, cumpliendo así la "vocación política del arte concreto [...] [:] prácticas artísticas subversivas que, sustentándose en la relativa autonomía del arte, pretenden instalar nuevas formas de relación entre el arte y la vida social" (Lucena 2011: 90-91).

Por eso, nueva visión plantea en su primer editorial la síntesis de las artes visuales, relegando el resto. Si bien se publica un artículo sobre poesía a cargo de Edgar Bayley - poeta hermano de Maldonado- y salen otros sobre música dodecafónica que firma Juan Carlos Paz, estas expresiones concretaban el propósito de "ser también tribuna para quienes en otros campos de la creación artística cumplan una tarea renovadora de similar contenido" (nueva visión, $\left.\mathrm{n}^{\circ} 1,1951\right)$. El propósito de esas inclusiones era resaltar una marca de modernidad en todas las áreas, para generar una atmósfera de innovación general y otorgar legitimación interartística, es decir, autorizar horizontalmente las prácticas novedosas de una disciplina mediante el modelo de otra.

El derrotero de Maldonado como artista/diseñador puede interpretarse en todo momento entre las dos alas del constructivismo: su trayecto va desde las concepciones de los hermanos Gabo y Pevsner a las de Tatlín y

\footnotetext{
${ }^{4}$ Cabe destacar dos intervenciones de Maldonado en Orientación, el órgano del PC, que pueden considerarse una transición entre el ideal constructivista de Gabo y Pevsner y el de Tatlín y Ródchenko, que lo guiaría hacia el diseño. Se trata de los fotomontajes que realizó para ilustrar dos números especiales en noviembre de 1946 y enero de 1947. Como señala Lucena (2015), el partido requería ilustraciones figurativas y el artista consideraba inútil la representación desde la existencia de la fotografía. Por eso, recurrió al fotomontaje de propaganda, una técnica constructivista, cuya yuxtaposición potenciaba el poder documental para la comunicación de masas. Esta fue una de sus primeras experiencias con una disciplina que, lindante con el diseño, combina la técnica y el trabajo artesanal, y cuyo destino es masivo, poco antes de su viaje a Europa.

${ }^{5}$ La síntesis de las artes visuales era un tópico recurrente en la reciente tradición arquitectónica y del diseño: desde Art \& Crafts hasta la Bauhaus, pasando por el constructivismo y De Stijl, todos favorecieron un trabajo conjunto de las áreas proyectuales, que repusiera una experiencia orgánica del quehacer artístico e, incluso, borrara la distinción entre las Bellas Artes y las artes aplicadas (Pevsner 2000, Rancière 2013).
} 
Ródchenko. En 1920, el primero publicó el Manifiesto del realismo, titulado así no porque adscribiera a la tendencia mimética, sino porque consideraba que su arte no representativo no provenía de la abstracción de una realidad, sino que era una realidad en sí misma, nueva. Para Gabo, el arte tenía un valor absoluto propio y una raíz, la vida, entendida como energía irracional (De Micheli 2000) universal. Una década después, Theo van Doesburg utilizaría los mismos fundamentos para denominar concreto a su arte, la tendencia en la que Maldonado enrolaría su práctica.

Tatlín, en cambio, se sintió interpelado por la Revolución para generar un arte que se adaptase a la nueva realidad soviética o, mejor, que contribuyera a modificarla de acuerdo con los cánones socialistas. Como sus compañeros del Frente de Izquierda de las Artes (Lef) y tan influenciado por las ideas de Bogdánov como Gabo y Pevsner (De Micheli 2000), consideraba que era preciso salir del individualismo y que el artista debía integrarse como un trabajador más al conjunto de la sociedad. Por eso,

Tatlín y sus seguidores propugnaban [...] la abolición del arte en cuanto tal, considerándolo como un estetismo burgués superado, e incitaban a los artistas a dedicarse a una actividad directamente útil a la sociedad, $[. .$.$] a aquellas formas que tuvieran relación con la vida: a la publicidad, a la$ composición tipográfica, a la arquitectura, a la producción industrial (De Micheli 2000: 231).

Estas ideas no llegaron directamente a Maldonado. Según cuenta, junto a su hermano Edgar Bayley, solían hurgar en los húmedos papeles que habían cruzado el Atlántico con los inmigrantes $\mathrm{y}$, antes de cumplir los 20 años, habían armado una red de información sobre las innovaciones artísticas del siglo a partir de documentos y publicaciones sobre el constructivismo, la Bauhaus, el cubismo y el arte abstracto en general, entre otros movimientos. Estas inquietudes habían dirigido su interés hacia Europa oriental. Pero la segunda posguerra y el comunismo completamente desplegado en Rusia empezaban a mostrar que las disciplinas constructivistas desarrolladas para asentar la vida socialista florecían mejor en los fértiles mercados del capitalismo.

\section{De Rusia a Estados Unidos}

Dirigida casi en su totalidad por Tomás Maldonado, nueva visión (1951-1957) tuvo el objetivo de modernizar los discursos sobre las artes visuales y el tratamiento de la forma que las reunía. Pero no era una simple actualización que las equiparara con las tendencias europeas. El cambio de perspectiva ofrecido por las artes proyectuales, que colocaba en un mismo nivel las disciplinas, aplanando las jerarquías, llevaba a plantear problemas que redefinían la praxis artística, su inscripción y su sentido social. Este enfoque era ya un posicionamiento, porque establecía un nuevo papel para el arte y el artista, que manejaba más de un lenguaje y trabajaba casi como uno más. El estilo gráfico y el tono de los textos estaba marcado por experiencias recientes con igual propósito renovador -como la revista Ciclo (1948) o el Boletín del Centro de Estudiantes de Arquitectura (CEA) — de las que Maldonado \& Co. habían participado (Lucena 2011; García 2011; Méndez Mosquera y García 2007).

Con el trasfondo lejano del artista renacentista que manejaba varias disciplinas y procedimientos, y sobre la base cercana de la experiencia rusa del productivismo, el modelo de la Bauhaus que Maldonado había terminado de integrar durante su viaje a través del contacto con sus ex alumnos, fue un eje vertebrador en los inicios de la publicación. La mítica escuela alemana era una referencia para las más importantes instituciones de diseño del mundo, aunque su eclecticismo se aplicaba de diferentes formas cada vez (Huff 2007). El propósito era elevar la práctica artesanal y técnica al estatuto de arte enfatizando la producción colaborativa, a fin de abandonar "las pretensiones clasistas que querían erigir una arrogante barrera entre artesanos y artistas" para crear "todos juntos la nueva estructura del futuro" (Gropius 1998 [1919]: 60). La tradición de la "restauración de la unidad arte" (Rancière 2013: 161), que pretendía reunir las artes aplicadas y las bellas artes, implicaba un arte colaborativo no en el sentido de "un arte para el pueblo", sino un "arte al servicio de fines determinados por la sociedad. [...] La 'política' del arte social se sitúa allí: en el rechazo de una distinción propia del arte y, por lo tanto, también de las distinciones entre las artes nobles y no nobles" (Rancière 2013: 161-162).

El número 1 de nueva visión está imbuido de estas cuestiones. Ernesto N. Rogers subraya la intención de borrar la distinción entre las artes en su artículo "Unidad en Max Bill" (1951), cuando resalta el dominio de los oficios del suizo como método para encarar los problemas del arte. Asimismo, si bien existe en la publicación una conciencia de que el diseño industrial únicamente puede florecer en la producción en serie, persiste como modelo la producción colaborativa que rompa con el individualismo. El artículo de César Janello, así lo expresa: "La colaboración entre el constructor, el pintor y el escultor puede ser muy eficaz, 
pero para llegar a ella es necesario superar muchos prejuicios individualistas y románticos -o puramente comerciales- y trabajar con humildad en forma colectiva aunque diversamente..." (1951: 9).

La homologación del individualismo, de lo considerado romántico y de lo comercial expone la idea de que el arte puede interferir en la vida no solo a través de sus obras sino mediante una praxis colaborativa, alejada de la sociedad de consumo o, por lo menos, morigerando sus consecuencias negativas. Se trataba de generar las condiciones para una producción y una recepción del arte colectivas como modo de subvertir la racionalidad alienante capitalista. Por eso, el artículo dedicado al "Diseño industrial en São Paulo", P. M. Bardi rescata la experiencia brasileña de "conquistar la calle", de buscar "la adhesión del espíritu popular" (1951: 9). En el artículo central, "Actualidad y porvenir del arte concreto", Maldonado critica el dogmatismo de la vanguardia y la búsqueda de novedades vacías, en consonancia con su inquietud por generar una apertura crítica. También se manifiesta a favor de fomentar la congruencia entre la praxis artística y su teorización, algo que no puede darse con los preconceptos de un dogma. Por eso, define el arte concreto como un método abierto a diferentes aplicaciones, lo que permitiría tramarlo con un urbanismo integral para incidir socialmente. Esta intervención se contrapondría al arte social o, como prefiere llamarlo, "arte alegato", aunque igualmente implica una ética "porque el hacer artístico -como todo hacer- equivale a tomar partido" (1951: 7). Producción y recepción colectivas, responsabilidad social: la revista va en la línea productivista.

La relación que Maldonado mantenía con Bill, así como su interés de estrecharla y de posicionarse en el ambiente europeo, hicieron que la opinión del suizo determinara el futuro de la revista. Un cambio en el diseño gráfico de mayor pureza reemplazó en la tapa los bloques blancos, verdes y negros, y la fotografía central por un solo plano monocromático cuyo color varía en cada número con unas pocas líneas blancas y negras, y la organización del contenido (García 2011, Méndez Mosquera y García 2007). Mientras el número 1 llevaba el subtítulo "revista de cultura visual", el agregado de "artes / arquitectura / diseño industrial / tipografía" y la incorporación en el comité de redacción de los arquitectos Juan Manuel Borthagaray, Francisco Bullrich, Jorge Goldemberg y Jorge Grisetti, todos miembros de la oam, ajustó el objetivo modernizador.

El cambio no fue solo gráfico. Sin editoriales o pronunciamientos, los textos muestran un giro gradual. En el número 2-3, el Arquitecto Juan Kurchan define el equipo como "múltiples voluntades individualmente diferenciadas, aunadas circunstancialmente en el logro de un objetivo común" (1953: 10; subrayado propio), muy lejos del trabajo mancomunado. "El diseño industrial y las ventas", artículo del diseñador estadounidense George Nelson (1953), argumenta que el origen del diseño industrial en su país ha sido la actividad comercial. Aunque señala la responsabilidad social del diseñador, por su influencia en el público y en la organización de la fábrica, determina un origen desviado de las vanguardias, enclavado en el corazón de la economía capitalista, la sociedad de consumo.

Algunos estudios sobre nueva visión sostienen que las referencias a Estados Unidos son marginales, a favor de una mirada puesta sobre la producción de Europa Central (Deambrosis 2011, 2006). Sin embargo, de allí en adelante, se verifican frecuentes alusiones al diseño estadounidense que subrayan los aspectos económicos y sociales favorables para su desarrollo en ese país ${ }^{6}$. En esta misma línea, la revista presenta la trayectoria de varios artistas europeos del Movimiento Moderno, herederos de las vanguardias rusas, que recalaron en Estados Unidos por causas políticas. Tal es el caso de Walter Gropius y Miës van der Rohe en el número 4. Ambos ex directores de la Bauhaus se encontraban allí desde 1937, convocados por la Universidad de Harvard y expulsados de Alemania por el nazismo ${ }^{7}$.

El número siguiente se abre con una extensa nota sobre Xanti Schawinsky, un multifacético artista, que condensaba la síntesis de las artes: pintor, escenógrafo, performer, precursor del happening, diseñador gráfico y de vestuario. Alumno y docente de la Bauhaus, también había llegado a Estados Unidos huyendo del nazismo. El número 8 presenta una nota sobre Josef Albers, otro ex Bauhaus emigrado a ese país. Sigue "Dos obras y una conferencia" de Richard Neutra (1955), arquitecto austríaco-estadounidense determinante

\footnotetext{
${ }^{6}$ Una nota sobre el “'Buen diseño' en el MART de Chicago” abre el no 4 y hace hincapié sobre la conjunción de la función, la confección, el precio y la influencia sobre el público; el artículo "Dos exposiciones en el Museo de Arte de Nueva York" en el n 5 presenta sugestivas fotografías de salas atestadas de sillas ultra modernas; una nota sobre los diseños de George Nelson en el $n^{\circ} 6$ destaca la fuerte industrialización estadounidense como impulsora de esas creaciones; etcétera.

${ }^{7}$ El texto publicado de Gropius subraya su rechazo de los dogmas; condena los abusos de la producción a gran escala; habla de la responsabilidad de educar, así como de la importancia del trabajo en equipo, que equilibra la cuestión comunitaria y el individualismo burgués. También agradece la hospitalidad estadounidense y destaca el país como ámbito de experimentación.
} 
para el Movimiento Moderno y el estilo americano, que propone una arquitectura de recepción y usufructo individual, fines exclusivamente burgueses:

...consideremos por un momento cómo experimentamos la casa más simple. Nos acercamos a ella después de haber estacionado el coche en el cordón de la vereda. [...]

El diseñador, el planeador, el arquitecto, está peligrosa y responsablemente al servicio de su cliente. Aun después que se retira, cobrando su honorario, y cuando aparentemente cae en el olvido, este peligroso personaje acompaña en realidad a su víctima veinticuatro horas al día [...]. La mayoría de sus actos [...] significan amenaza o promesa, daño o beneficio, complicaciones futuras o confortable desenvolvimiento de multitud de procesos de la vida y -si recorremos el cuadro de nuestro atribulado mundo fabricado por el hombre-, la supervivencia de nuestra raza (Neutra 1955: 16-17).

Neutra concibe la vida únicamente en su versión de experiencia burguesa o, por lo menos, considera que los "medios contemporáneos en arquitectura" (1955: 15) reproducen solo esa forma de vida. De allí que defina al público como "masa consumidora de seres humanos" (1955: 17) y que resalte el rasgo mercantil de las relaciones que los arquitectos y los diseñadores establecen a través de sus obras. De modo que el compromiso que la revista había expuesto muchas veces como ética social, responsable del desarrollo de una comunidad, se expresa ya a fines de 1955 como una ética comercial. nueva visión replica precipitadamente el trayecto de los artistas europeos que habían recalado en Estados Unidos y se habían sometido a una paulatina “desocialización". En otras palabras, reproduce en su discurso el movimiento de despolitización de la vanguardia, tal como lo explica Huyssen:

...durante la Guerra Fría, y especialmente después de la aparición de la noción del fin de las ideologías, se perdió la energía política de la vanguardia histórica y el centro de la innovación artística se desplazó de Europa a Estados Unidos [...], país donde la rebelión contra una herencia cultural burguesa no habría tenido sentido en términos políticos ni artísticos (2006: 23-24).

La traslación discursiva se advierte también en otros aspectos: la revista matiza los dogmatismos; devuelve la subjetividad expresiva a la pintura -algo que antes consideraban idealista e individualizante-; no rechaza la idea de la arquitectura con fines burgueses ni el diseño supeditado al mercado, y corre el fundamento teórico del arte desde el materialismo histórico a una ciencia despolitizada.

De acuerdo con Huyssen, el conformismo sometió la tradición vanguardista en las sociedades capitalistas avanzadas hasta convertirla en un instrumento de las clases dominantes: “...no ha hecho sino obliterar el ímpetu iconoclasta y subversivo de la vanguardia histórica [...] [que] se manifiesta en la amplia despolitización del arte posterior a la Segunda Guerra Mundial y su institucionalización como cultura administrada" (2006: 20). Esto no ocurrió en los movimientos latinoamericanos que, inmersos en capitalismos menos desarrollados -lo que implicó una relación diferente con la cultura de masas y con el tejido social-, sufrieron una politización creciente en la misma época, que se cristalizó en el llamado del gobierno revolucionario de Cuba a intelectuales y artistas en la década de 1960 (Gilman 2003). En el caso aquí tratado, sin embargo, la mutación del discurso político fue consecuencia de una evolución de la praxis artística hacia la profesionalización de las disciplinas proyectuales, cuyo desarrollo había encontrado terreno fértil en la sociedad de consumo y se había obturado con la apuesta por la industria pesada del régimen soviético.

\section{De la política a la ciencia}

A continuación de la primera nota del número 6 sobre la Casa Curuchet que Le Corbusier construyó en La Plata (Borthagaray 1955), un artículo de Mário Pedrosa titulado "Las relaciones entre la ciencia y el arte" equipara como complementarias ambas actividades. La ciencia y la técnica cautivaron a la vanguardia desde sus inicios y Huyssen señala que incluso "puede haber sido una nueva experiencia de la tecnología lo que encendió la chispa de la vanguardia, más que el mero desarrollo inmanente de las fuerzas artísticas de 
producción" (2006: 30-31). Aunque este supuesto es limitado para dar cuenta de un fenómeno tan complejo, tanto la experiencia como la imaginación tecnológica marcaron un pulso de cambio que la vanguardia pretendía alcanzar. En el Movimiento Moderno, la relación con la tecnología fue ambivalente (Pevsner $2000)^{8}$. A esta altura de los debates, el problema estaba bastante zanjado desde que la mecanización permitía abaratar costos de producción y democratizar los bienes de uso, incluso para el realismo socialista que había adoptado la exaltación industrial.

La cuestión era, para Pedrosa, colocar la ciencia como reguladora de la praxis artística, en coincidencia con las preocupaciones de nueva visión. Maldonado había manifestado en el número 1 la necesidad de que el arte concreto se vinculara con la ciencia para participar de sus avances. A partir de 1944, luego de su exilio en Estados Unidos, el crítico brasileño había hecho un viraje similar: sin abandonar sus preocupaciones político-sociales de izquierda, apostaba ahora a la potencia performativa del arte (D'Assunção Barros 2008) y buscaba su estatuto científico, en la misma línea que Bill. Unos años antes, en 1950, la revista Ver y Estimar había publicado una colaboración del artista suizo donde rechazaba la posibilidad de canalizar los problemas políticos y sociales a través del arte porque suponía un retorno hacia formas expresivas ya perimidas. En su lugar, proponía desarrollar un arte de base matemática, como un modo de integrar el pensamiento racional a una actividad relacionada con el sentimiento. La matemática funcionaba como ordenadora de la emoción a través de la geometría, entendida como relación de posiciones en el plano:

La matemática, además de ser uno de los reguladores principales del sentimiento primario y, en consecuencia, uno de los medios más eficientes para el conocimiento de la realidad objetiva, es, al mismo tiempo, ciencia de relaciones, de comportamiento de cosa o cosas, de grupo a grupo, de movimiento a movimiento (Bill 1950: 5).

Con esa función reguladora, pretendía que la ciencia aprehendiera la realidad, papel que, poco antes, había cumplido el marxismo para los concretos argentinos. El proceso de profesionalización de las disciplinas proyectuales tenía entonces dos caras: retrocedían las ideas de izquierda y el fundamento científico-técnico ganaba terreno. Con artículos como "Filosofía de la técnica", de Max Bense y otros, el tema se vuelve recurrente en el número 8 de fines de 1955.

Esto era contemporáneo de una situación política nacional que se complejizaba desde que la Revolución Libertadora mostraba sus contradicciones en la proscripción del peronismo. La revista se había pronunciado en el número anterior: en una hoja suelta, había manifestado su acuerdo con el final de "la ensordecedora demagogia que destruyó y desvirtuó los conductos de la expresión [...] [que] condujeron a un profundo deterioro de las formas de vida y comunicación en las que se asienta toda actividad de la cultura" (1955: s.p.). Pero también advertían sobre la necesidad de no restaurar la situación anterior al peronismo, para garantizar la subsistencia de manifestaciones surgidas en el periodo, preservar la libre expresión y promover una "profunda reforma institucional" de la "Universidad Nacional verdaderamente integrada a la vida social" (s.p.).

La declaración llama especialmente la atención porque en los números previos hay una completa ausencia de referencias a la política nacional. Pero ese silencio, así como el afianzamiento de la ciencia por sobre el marxismo como fundamento, probablemente no era a causa de una intención política local o directa, sino que se vinculaba con la influencia de Maldonado y sus intereses, que ya no residía en Buenos Aires sino en Ulm desde 1954, aunque continuaba supervisando sus contenidos como director de la publicación. De hecho, su aporte a la pedagogía de la Hochschule für Gestaltung (HfG, Escuela Superior de Diseño) de Ulm consistiría en colocar la ciencia como fundamento del diseño, algo que se convertiría en una parte central de su legado a la teoría de esta disciplina (Huff 2007, Bonsiepe 2007).

El catálogo inicial de la Editorial Nueva Visión ya señalaba este interés en ensayos sobre los últimos avances de la ciencia. Dirigida por el arquitecto Jorge Grisetti desde su fundación en 1955, estaba ligada a

\footnotetext{
${ }^{8}$ El Manifiesto comunista (1848) reconoce como una de las fuentes del sojuzgamiento del proletariado a la máquina, que transformó las condiciones de producción desde el taller del artesano hasta la fábrica industrial. La consecuencia fue una reificación de las relaciones y la alienación de los individuos. Para el marxismo, el artista no detenta una función especial fuera de su propia condición de clase, porque la creación artística está subsumida dentro de la categoría general de trabajo humano (Huyssen 2006). La ideología burguesa, por el contrario, identificó el avance técnico como la vía para alcanzar el progreso de la humanidad. El socialismo, por su parte, tuvo una actitud de resistencia a la tecnología, al invocar modos antiguos de producción (Pevsner 2000, Williams 1981). Arts\&Crafts experimentó la paradoja de que la vuelta a las técnicas artesanales encarecían tanto los productos que se volvieron accesibles solo para las clases altas.
} 
los mismos intereses de modernización y formación de un público que la revista, aunque su espectro era más amplio: tenía el objetivo de formar un lector moderno no solo en materia de artes proyectuales, sino en cuanto a las últimas innovaciones en diferentes áreas, que iban desde la filosofía y la historia, hasta las incipientes ciencias sociales y la técnica. El propósito era ampliar el abanico de preocupaciones profesionales, con la convicción de que así sería posible preparar expertos y públicos con una conciencia crítica, capaces de recibir y procesar las novedades".

Los títulos que acompañan la colección "Ideas de nuestro tiempo" subrayan el presente: “...esta colección aspira a ser un panorama de la actualidad intelectual en sus distintos matices. Los volúmenes [...] se dirigen al hombre de cultura general que quiere conocer las ideas de nuestro tiempo sobre las cuestiones humanas permanentes y sobre las cuestiones que a la inteligencia del hombre plantea la variada realidad social y espiritual de este siglo" ". Sin embargo, títulos como El hombre y la técnica (Brinkman 1955), Arte y técnica (Mumford 1957), Hombres, máquinas e historia (Samuel 1957), La cibernética. Cerebros y máquinas (Slukin 1957), Maquinismo y filosofía (Schuhl 1957), Introducción a la cibernética (Asby 1960), señalaban una inclinación por el tema y por una incipiente informática. Desde el libro de Slukin sobre "cerebros electrónicos", "que podrían desempeñar un casi imprevisible papel en un caso de conflicto armado"11, hasta el de Schuhl, que analiza la transformación de la conciencia a partir de la mecánica, la ciencia y la técnica marcan el pulso de lo nuevo y de todo progreso. Los textos discuten la incertidumbre que generan los avances, pero es allí donde se gesta el futuro que luego se verá plasmado en los modos de relación social, regulados así por una política de la ciencia.

\section{Una plataforma de lanzamiento editorial}

Este desplazamiento de las ideas de izquierda como fundamento artístico y como regulación de la vida puede entenderse en el contexto de la segunda posguerra, cuando el mundo, horrorizado por los crímenes del nazismo y perplejo por el avance de la URSS estalinista, procuraba morigerar los extremismos y repudiar las formas totalitarias. Además, las disciplinas proyectuales necesitaban sortear la situación política y económica local para afianzar su profesionalización. O bien, puede entenderse en el marco más restringido de intereses particulares que, moldeados en esa coyuntura, buscaban trascenderla. La misma revista expone un motivo que justifica ese giro en los artículos sobre la HfG de Ulm de los números 4 y 7.

En "Educación y creación", Max Bill rescata lo que le interesa de la Bauhaus y del modelo educativo de Lloyd Wright, "un método de trabajo que plantea los problemas individuales y acentúa la formación de personalidades independientes", para concluir que "experiencia individual y trabajo de grupo se complementan" (1953: 8), una suerte de síntesis entre comunidad y espíritu de empresa que planifica para la futura institución en Ulm. El número 7 expone los avances de la construcción de la HfG en varias notas. La de Maldonado se aleja del modelo Bauhaus y también toma distancia del planificado por Moholy Nagy en Chicago, porque busca demasiado la expresividad del alumno y no va detrás de las formas socialmente legítimas. Además, señala que "el artista, aun trabajando para la producción en serie, tiene que defender siempre sus deberes para con la sociedad" (Maldonado 1955: 5), supeditando el adecuado desarrollo de las formas sociales a la ética individual.

A pesar de las condiciones adversas, Maldonado tenía intenciones de insertarse en la HfG. Como ha manifestado: "Alemania estaba toda destruida. Terminada la guerra, todos los argentinos querían ir a París, Londres y Madrid. Y yo invece he sido invitado a ir ahí, pero de todas maneras, he optado por ir a un país destruido por la guerra, que la perdió. Yo voy a un lugar complicado y eso es parte también de la mentalidad. Era una opción cultural" "2. El camino sacrificado valía la pena porque Alemania era la cuna de todas las corrientes plásticas y de diseño que le interesaban, un lugar de frontera política y cultural: no solo albergaba la línea de separación entre el mundo capitalista y el comunista, sino que unas décadas atrás había sido la

\footnotetext{
${ }^{9}$ Un objetivo similar advierte Bonsiepe (2007) en las conferencias que se dictaban en el marco de los llamados "Seminarios de los miércoles" en la HfG, que originalmente figuraban en el plan de estudios como "Integración Cultural". Allí, participaron numerosas personalidades de la cultura, la filosofía, escritores, científicos, historiadores, ingenieros, psicólogos, publicistas, matemáticos, etc. que aun hoy gozan de renombre internacional. Maldonado habría tenido la intención de presentar un renovado concepto de cultura, inclinado hacia la interdisciplinariedad, que rompía con el tradicional concepto de cultura.

${ }^{10}$ Nota de promoción de la colección en Slukin (1957: 213).

${ }^{11}$ Nota de promoción del libro de Slukin (1957: 212).

${ }^{12}$ En entrevista personal. Milán, 26 de marzo de 2014.
} 
puerta de entrada de las innovaciones rusas a occidente. La inclusión en la Bauhaus de Kandinsky, que había participado en la creación de varias escuelas de arte durante la Revolución Rusa; la llegada de Moholy-Nagy, con su bagaje constructivista; la permanencia de El Lissitsky entre 1921 y 1924 como embajador cultural; el contacto de Malévich con la Bauhaus de Dessau durante su viaje en 1926 y el de Gabo y Pevsner entre 1922 y 1923 (De Micheli 2000) fueron puentes que contribuyeron a difundir la vanguardia rusa, así como a establecer relaciones entre los artistas.

Pero el carácter fronterizo del país estaba más candente que nunca, como trinchera de la Guerra Fría, y alcanzaba todos los rincones de la vida social y cultural. Incluso la articulación entre la deriva productivista y el nuevo modelo capitalista que exponía Maldonado en su artículo estaba sustentada por esa coyuntura: la construcción de la HfG fue financiada por la Fundación Hermanos Scholl, conformada en honor a los hermanos que resistieron pacíficamente el nazismo y fueron guillotinados en 1943, y por la donación del Alto Comisionado estadounidense, a cargo John Mc Cloy, que junto con el Reino Unido y Francia regulaba y supervisaba el desarrollo de la reciente República Federal de Alemania. El contexto político de frontera, así como el proceso acelerado de reconstrucción asistida por las naciones ganadoras de la guerra, explican que tanto Bill como Maldonado quisieran mostrar un plan más acorde al país benefactor. En esa línea, nueva visión avanzó hacia una concepción de la práctica artístico-industrial más vinculada a un ideal humanista, liberal y progresista, que se acomodaba al maniqueísmo de la política mundial.

Esto puede constatarse en la última aparición de la revista de la que Maldonado ya se había apartado. El número 9 de 1957 se inclina más hacia la arquitectura (Deambrosis 2011) y se manifiesta más abiertamente de izquierda. No se trata solamente de la predominancia del tema, sino de una diferencia discursiva: mientras que en los números anteriores, en los que incidía Maldonado, las notas sobre arquitectura tenían un tratamiento técnico y descriptivo, en este ejemplar sobresalen los posicionamientos, las opiniones y las críticas, tanto al presentar la obra de un arquitecto reconocido como Amancio Williams, como al considerar el particular concepto del edificio del Hogar Obrero sobre Avenida Rivadavia. Por primera vez la publicación se abre con tres breves editoriales que toman partido por circunstancias políticas específicas y buscan sentar posición desde un lugar tan profesional como político ${ }^{13}$.

Más allá del posicionamiento sobre la coyuntura, las ideas de izquierda vuelven con fuerza en el artículo de Francisco Bullrich, "Algunos problemas del diseño", donde hace una reconstrucción histórica de la disciplina y de la discusión sobre la estética de la máquina desde una perspectiva materialista. El artículo rebate la hipótesis sobre el origen comercial, tal como lo exponía George Nelson unos números atrás:

El primer manifiesto del Deutsches Werkbund en 1911 [...] decía que un diseño racional permitiría desplazar de los mercados a los competidores menos avanzados y que, de esta manera, la industria alemana podría aumentar sus ventas y lograr mayores ganancias. [...] Desgraciadamente, el argumento, además de falso, era peligroso.

Era falso porque la historia de estos últimos cincuenta años ha demostrado que, apenas se tomaron medidas de racionalización en la industria alemana, las industrias de otros países hicieron lo propio a los pocos años [...]. Y era peligroso porque, realizado el ciclo completo, los industriales, desesperados por aumentar sus ventas, se dedicaron a cambiar en forma "sensacional" -entiéndase artificial-sus productos (Bullrich 1957: 21).

El aumento de las ventas no era la fuente y el estímulo del diseño, porque este no escapaba a la competencia en una economía de mercado. Más aún, el propósito de vender más habría desvirtuado el objetivo del diseño, que pretende embellecer los productos sin desestimar la función y habría generado artículos afectados y de gusto dudoso. Por eso, el fin comercial era un problema en lugar del origen de la disciplina, ya que desvirtuaba su práctica y los productos. El diseñador tenía para Bullrich -y para el resto del grupo, como se ha visto en este artículo- la responsabilidad de crear los nuevos valores culturales que sustituirían los tradicionales, por lo que no podía abandonarse a "la novedad por la novedad misma" (1957: 22), sino que debía guiar e instruir al público.

\footnotetext{
${ }^{13}$ El primero, "Modificaciones al Código de Edificación", critica al presidente de la Comisión Nacional de la Vivienda por su propuesta para la construcción en una zona de la Ciudad de Buenos Aires. El segundo, "Se han entregado premios de fachadas", festeja la decisión política de hacer los concursos, y "Planeamiento en Misiones", apoya la planificación urbanística y el llamado a concursos de obras del gobierno provincial.
} 
Las ideas socialistas están presentes también al momento de valorar el edificio de la Cooperativa "El Hogar Obrero" de la avenida Rivadavia. Entre apreciaciones y críticas técnicas, el artículo destaca las dependencias generales de inspiración socialista: un lavadero mecánico, un comedor y una cocina centrales, y una guardería infantil, todos parte de una organización comunitaria que permitía que las viviendas no contaran con cuarto de servicio. El artículo resalta: "Estos servicios generales plantean una experiencia de gran utilidad en nuestro país, pues desarrollan orgánicamente las relaciones colectivas del grupo social domiciliario y servirán como dato básico para futuros planteos" (Beretervide et al. 1957: 28) ${ }^{14}$. De modo que el texto rescata la inspiración socialista del proyecto, que tal como la "nueva vida cotidiana" de la Revolución Rusa (novi byt), suponía la colectivización de las tareas domésticas esclavizantes ${ }^{15}$.

Mientras la revista estuvo supervisada por Maldonado, sus contenidos fueron morigerando las posiciones de izquierda, no porque el diseñador y teórico argentino hubiera cambiado su postura política, sino porque necesitaba una carta de presentación que no desentonara con el contexto alemán de posguerra. En tiempos de Guerra Fría, cualquier posicionamiento en falso podía derretir los puentes que establecían las relaciones personales e institucionales en un entorno de frontera ideológica. Por eso, el alejamiento de Maldonado dio más libertad a la manifestación de los intereses políticos del grupo. Sin embargo, el renacer socialista fue breve no porque el grupo editor haya modificado su postura, sino porque la revista se discontinuó definitivamente en 1957, dejando al Diseño Industrial argentino en germen a causa del escaso desarrollo de la industria.

Por los menos, hasta la creación de la carrera de Diseño Industrial en la Universidad de Buenos Aires en la década de 1980. De hecho, la modernización que produjo este grupo tuvo su más importante correlato en el ámbito académico: durante los años sesenta varios de sus miembros fueron figuras claves de la renovación de la Facultad de Arquitectura de la UBA y sentaron las bases para el desarrollo de la Escuela de Arquitectura y Planeamiento de la Universidad de Rosario ${ }^{16}$. La creación de la carrera de Diseño Industrial estuvo igualmente influida por este trayecto intelectual, algo que puede constatarse al verificar la coincidencia casi total del plan de estudios inicial con el currículo de la HfG de Ulm. Esta deriva académica resulta consistente también con el derrotero de las ideas de izquierda.

Las fluctuaciones entre la ciencia y la política como fundamento de la intervención social de las artes proyectuales indican oscilaciones discursivas en los posicionamientos políticos de la publicación, que obedecían a diferentes configuraciones del campo profesional. Mientras Maldonado necesitaba moderar las posiciones extremas para no desentonar en el contexto de la reconstrucción alemana, los arquitectos de la oam tenían que pisar fuerte para hacerse un lugar en la planificación urbanística y la construcción de edificios públicos (Deambrosis 2011). De allí, sus posiciones con respecto a la política nacional. La rectificación de la postura ideológica en el último número probablemente responda a un reposicionamiento y un sinceramiento luego de la salida de Maldonado. Ya fuera en la HfG o el ámbito local, el proyecto editorial era una plataforma para asentar ideas, fijar posturas, incidir e insertarse en el ámbito profesional, todas acciones políticas

\footnotetext{
${ }^{14}$ Otro caso de reproducción de esta ideología es la publicación del discurso de cierre de la Conferencia Nacional de Arquitectura de Polonia, a cargo del Presidente del Consejo de Ministros, J. Cyrankiewicz, que también es una muestra de la posición ideológica del nuevo grupo editor. El texto critica el "lujo de fachada", la "falsa monumentalidad" de la arquitectura polaca hasta hacía poco, a pesar de que "el socialismo requiere [...] una arquitectura sellada de simplicidad y modestia, donde la fachada se armonice con el exterior, el etilo con la materia, la silueta con el entorno, el proyecto con el sentido común" (1957: 33). En lugar de esto llama a utilizar los métodos industrializados de construcción, y a practicar la construcción cooperativa, destacando la responsabilidad de los arquitectos en el desarrollo de una edificación "económica, práctica y estética" (33). En definitiva, el texto expone un modo de construcción socialista como modelo a seguir.

15 "El libro Cuestiones de la vida cotidiana, escrito en 1923 por el líder del Partido León Trotsky, argumentaba que los grandes ideales de la revolución no se podrían llevar a cabo si la gente no cambiaba la manera de vivir su vida en los niveles más básicos y cotidianos, en sus hogares y en sus familias. A tal fin, pedía que las mujeres se liberasen de la esclavitud doméstica, que el cuidado infantil se socializara y que el matrimonio se diferenciara de las relaciones de propiedad privadas. Estas ideas se visualizaban en los numerosos carteles de propaganda que en ese periodo promocionaban la novi byt, contrastando imágenes de mujeres esclavizadas por objetos domésticos tradicionales, por un lado, e imágenes de mujeres que se movían con libertad en los espacios diáfanos — si bien todavía, en gran parte, tan solo imaginados- de comedores públicos, lavanderías y guarderías, por otro. [...] Los problemas de la byt eran problemas de mujeres, que habían de ser resueltos liberando la vida material de su control por parte de los individuos y de la familia, mediante la construcción de instituciones colectivas" (Kiaer 2010: 25-26).

${ }^{16}$ Juan Manuel Borthagaray fue profesor titular de la Universidad Nacional del Litoral y de la Universidad de Buenos Aires, también fue decano de la Facultad de Arquitectura y Urbanismo (UBA) en los periodos 1986-1990 y 1990-1994; Francisco Bullrich fue miembro del Consejo Directivo de la FADU-UBA en 1960 e integró el Consejo Superior de la UBA en 1962; Jorge Goldemberg fue profesor de Sociología en la UNL y en la UBA, junto al profesor Gino Germani; la arquitecta Carmen Córdova fue la primera decana de la FADU-UBA entre 1994 y 1996; Horacio Baliero fue docente de la FADU-UBA entre 1963 y 1966, cuando emigró por la dictadura de Onganía, y al regreso de la democracia en 1983 fue titular de la cátedra de Diseño Arquitectónico (UBA) con tan importante influencia que aun hoy la cátedra conserva su nombre. El grupo también aportó una gran renovación a la fisonomía de la ciudad de Buenos Aires con edificios como la Biblioteca Nacional (Testa, Bullrich, Cazzaniga) y la sede del Instituto Di Tella (Testa, Bullrich), así como muchos edificios residenciales.
} 


\section{Referencias bibliográficas}

Ashby, William Ross (1960). Introducción a la cibernética. Buenos Aires: Ediciones Nueva Visión.

Bardi, P. M. (1951), “Diseño industrial en São Paulo", nueva visión, nº 1, diciembre de 1951, p. 9.

Beretervide, F., W. Acpsta, A. Felici y J. C. Ruiz (1957), "Edificio para una cooperativa de vivienda”, nueva visión, $\mathrm{n}^{\circ}$ 9, pp. 24-29.

Bill, Max (1953), "Educación y creación”, nueva visión, n 4, pp. 7-8.

Bill, Max (1950), "El pensamiento matemático en el arte de nuestro tiempo”, Ver y Estimar, n 17, mayo de 1950, pp.17.

Bonsiepe, Gui (2007), "La escuela de diseño de Ulm (Hochshule für Gestaltung) como experimento de innovación cultural", en Tomás Maldonado, un itinerario. Buenos Aires: Museo Nacional de Bellas Artes, pp. 122-135.

Brinkman, Donald (1955). El hombre y la técnica. Fundamentos para una filosofía de la técnica. Buenos Aires: Galatea-Nueva Visión.

Bortogaray, Juan Manuel (1955), “Casa Curuchet. Eva Perón, 1954. Le Corbusier”, nueva visión, n 6, pp. 7-13.

Bullrich, Francisco (1957), “Algunos problemas del diseño”, nueva visión, nº 9, pp. 20-23.

Cyrankiewicz, J. (1957), "Discurso de cierre de la Conferencia Nacional de Arquitectura de Polonia", nueva visión, $\mathrm{n}^{\circ}$ 9, p. 33.

D'Assunçao Barros, José (2008), "Mario Pedrosa e a crítica de arte no Brasil”, ARS (São Paulo), vol. 6, n 11, pp. 4060.

Disponible en: http://www.revistas.usp.br/ars/issue/view/256

Deambrosis, Federico (2006), “QQué hacer con los yanquis? Distintas recepciones de las experiencias y de los modelos estadounidenses en el medio arquitectónico argentino. Los casos de Nuestra Arquitectura y nv. nueva visión: 19511957”, en La arquitectura norteamericana, motor y espejo de la arquitectura española en el arranque de la modernidad (1940-1965). Actas preliminares. Pamplona: Escuela Técnica Superior de Arquitectura/Universidad de Navarra, pp. 103-110.

Deambrosis, Federico (2011). Nuevas visiones. Buenos Aires: Infinito.

De Micheli, Mario (2000). Las vanguardias artísticas del siglo XX. Madrid: Alianza.

García, María Amalia (2011). El arte abstracto. Buenos Aires: Siglo XXI.

Gilman, Claudia (2003). Entre la pluma y el fusil. Debates y dilemas del escritor revolucionario en América Latina. Buenos Aires: Siglo XXI.

GROPIUS (1998) [1919], "Manifiesto fundacional de la Bauhaus de Weimar”, en José Sáenz Botey. Arquitectura en el siglo XX. La construcción de la metáfora. Barcelona: Montesinos, p. 60.

Huff, William S. (2007), "Albers, Bill y Maldonado: el curso básico de la Escuela de Diseño de Ulm (HfG)", en Tomás Maldonado, un itinerario. Buenos Aires: Museo Nacional de Bellas Artes, pp. 104-121.

Huyssen, Andreas (2006). Después de la gran división. Modernismo, cultura de masas, posmodernismo. Buenos Aires: Adriana Hidalgo Editora.

Janello, César (1951), "Pintura, escultura y arquitectura", nueva visión, no 1, diciembre de 1951, p. 9.

Kiaer, Christina (2010), “«A la producción!»: los objetos socialistas del constructivismo ruso", en Ana Jiménez Jorquera y Marcelo Expósito. Los nuevos productivismos. Barcelona: Universitat Autònoma de Barcelona, pp. 2143.

Disponible en: http://transform.eipcp.net/transversal/0910/kiaer/es

Kurchan, Juan (1953), "La colaboración en el trabajo creador de arquitectura", nueva visión, n. 2-3, enero de 1953, p. 10.

Lucena, Daniela (2011), “Arte concreto y nueva visión: una lectura en clave política”, Aurora. Revista de Arte, Mídia e Política, $\mathrm{n}^{\circ}$ 10, pp. 86-101.

Disponible en: https://revistas.pucsp.br/aurora/issue/view/331/showToc

Lucena, Daniela (2015). Contaminación artística. Vanguardia concreta, comunismo y peronismo en los años 40. Buenos Aires: Biblos.

Longoni, Ana y Daniela Lucena (2003-2004), "De cómo el 'júbilo creador’ se trastocó en "desfachatez". El pasaje de Maldonado y los concretos por el Partido Comunista. 1945-1948”, Políticas de la Memoria, Cedinci, n 4, verano, pp. 116-128.

Maldonado, Tomás (1949), "El diseño y la vida social”, Cea. Boletín del Centro de Estudiantes de Arquitectura, $\mathrm{n}^{\circ} 2$, octubre, pp. 7-8.

Maldonado, Tomás (1951), “Actualidad y porvenir del arte concreto”, nueva visión, n 1, diciembre de 1951, pp. 5-8.

Maldonado, Tomás (1955), "La educación social del creador en la Escuela Superior de Diseño”, nueva visión, nº 7, pp. 5-6.

Méndez Mosquera, Carlos A. y María Amalia García (2007), "Notas sobre la revista nueva visión y sus recorridos", en Tomás Maldonado, un itinerario. Buenos Aires: Museo Nacional de Bellas Artes, pp. 178-189.

Mumford, Lewis (1957). Arte y técnica. Buenos Aires: Nueva Visión.

Nelson, Geoge (1953), "El diseño industrial y las ventas", nueva visión, no 2-3, pp. 19-24.

Neutra, Richard (1955), "Dos obras y una conferencia”, nueva visión, no 8, pp. 14-24.

Pevsner, Nikolaus (2000). Pioneros del diseño moderno. De William Morris a Walter Gropius. Buenos Aires: Infinito. 
Rancière, Jacques (2013). Aisthesis. Escenas del régimen estético del arte. Buenos Aires: Manantial. Rogers, Ernesto (1951), "Unidad en Max Bill”, nueva visión, nº 1, diciembre de 1951, pp. 11-12

Samuel, Lilley (1957). Hombres, máquinas e historia. Buenos Aires: Galatea-Nueva Visión.

Schuhl, Pierre (1957). Maquinismo y filosofía. Buenos Aires: Galatea-Nueva Visión.

Slukin, Wladyslaw (1957). La cibernética. Cerebros y máquinas, Buenos Aires: Galatea-Nueva Visión.

Williams, Raymond (1981). Cultura. Sociología de la comunicación y el arte. Buenos Aires: Paidós. 